\title{
Burnout among Iranian medical students: Prevalence and its relationship to personality dimensions and physical activity
}

\author{
Mohsen Khosravi \\ Department of Psychiatry and Clinical Psychology, Zahedan University of Medical Sciences, \\ Zahedan, Iran \\ This article is distributed under the terms of the Creative Commons Attribution Noncommercial License (CC BY-NC 4.0) which permits
} any noncommercial use, distribution, and reproduction in any medium, provided the original author(s) and source are credited.

\begin{abstract}
Several studies have shown the association between personality traits and academic burnout. But the main goal of the present study was to find out an experimental answer to the following questions: Is there a simple relationship between personality dimensions and academic burnout? Can physical activity affect this relationship?. In this cross-sectional correlational study, 417 medical students were selected from three major cities of Iran through stratified multistage sampling and assessed by demographic information form, Baecke Physical Activity Questionnaire, Temperament and Character Inventory, and Breso's Academic Burnout Questionnaire. Bivariate Pearson correlations and hierarchical linear regression were used to examine the relationships between academic burnout, personality traits, and physical activity. In this study, 400 medical students (39\% male and 61\% female) filled the questionnaires correctly. The total prevalence of academic burnout was 25.5\% $(n=102)$, with heterogeneous levels. Regression analysis indicated that in a multivariate model, being male $(\beta=0.08, p=0.013)$, higher years of medical school $(\beta=0.18, p<0.001)$, and lower scores in novelty seeking $(\beta=-0.53$, $\mathrm{p}=0.006)$, cooperativeness $(\beta=-0.55, \mathrm{p}=0.010)$, and physical activity $(\beta=-1.22, \mathrm{p}<0.001)$ could be attributed to higher scores of academic burnout. Furthermore, physical activity had a moderating role in "novelty seeking-academic burnout" $(\beta=-0.47, \quad p=0.044)$ and "cooperativeness-academic burnout" $(\beta=-0.89, \mathrm{p}=0.001)$ relationships $\left(\Delta \mathrm{R}^{2}=0.02, \mathrm{p}<0.001\right)$. The results suggested that male gender, higher years of medical school, and lower levels of novelty seeking, cooperativeness, and physical activity are associated with higher levels of academic burnout among Iranian medical students. Therefore, paying attention to male gender and individual difference factors, as well as planning for physical education classes during the medicine courses (especially in the last years of medical school), seems essential. However, more extensive investigations need to be carried out in this field through longitudinal studies.
\end{abstract}

Key Words: burnout, medical students, personality, physical activity.

Eur J Transl Myol 2021; 31 (1): 9411. doi: 10.4081/ejtm.2021.9411

A variety of factors may be associated with improved or impaired academic performance among medical students. One of the most recently studied factors is academic burnout. ${ }^{1}$ The concept of academic burnout was first introduced by Schaufeli et al. ${ }^{2}$ according to the comprehensive reports of Kafry and Pines on the high levels of burnout in university students. ${ }^{3}$ Academic burnout is conventionally characterized by a triad of symptoms, including high levels of exhaustion and cynicism, and low levels of professional efficacy. ${ }^{4-6}$ Such problematic conditions might have serious consequences, comprising decreased health-related quality of life, loss of motivation, deterioration in academic and social performance, job dissatisfaction, sleep disorders, anxiety, depression, use of illicit drugs, and suicidal thoughts. ${ }^{7-11}$ There are numerous studies on the significant prevalence of this syndrome during the medical courses. For example, a recent meta-analysis estimated the prevalence of academic burnout at a range from 7 to $75.2 \% .^{12}$ Despite multiple investigations on the prevalence of burnout phenomenon among medical students, there are few studies on its associated key factors, particularly internal factors. ${ }^{13}$ Nonetheless, the most recent explorations have demonstrated that two main types of factors, including external environmental and individual factors, can accelerate the development of academic burnout over the medical course., ${ }^{7,14}$ In further detail, Slivar's hypothesis states that external 
environmental factors are deeply connected with excessive learning-related activities. ${ }^{16}$ In contrast, Jacobs and Dodd's research highlighted a negative temperament effect on students' academic burnout and different reactions to similar stressful situations among them. ${ }^{17}$ They suggested that researchers should target the personality traits rather than focusing on external environmental factors involved in the academic burnout development. ${ }^{17}$ However, a limited number of studies on the prevention of academic burnout have evaluated the effect of personality factors, especially Cloninger's biopsychosocial model of personality. ${ }^{7}$ For instance, several inquiries revealed that academic burnout was positively correlated with harm avoidance (HA), and negatively correlated with self-directedness and cooperativeness. ${ }^{18-21}$ Furthermore, Yazici et al. showed that novelty seeking (NS) and persistence (PS) are linked to academic burnout. ${ }^{21}$ Only Stoyanov and Cloninger demonstrated that students with high PS exhibited more vulnerability to burnout syndrome. ${ }^{22}$ Although personality dimensions play a critical role in the development of burnout, this mental impairment is not caused by a specific factor. Based on recent studies, for instance, physical activities have been effective in preventing academic burnout, probably due to its remarkable impacts on mastery motive, negative thoughts, stress, and depression. ${ }^{23,24}$ In spite of the beneficial effects of physical activity on quality of life and mental health, the role of physical activity in reducing academic burnout among medical students is still uncertain. ${ }^{25,26}$ Academic burnout is a significant challenge among Iranian medical students; however, no specific study has yet examined its prevalence and associated factors.

Given the critical role of academic burnout in disrupting students' academic performance and imperiling their physical and psychological health, it is essential to identify factors relevant to this phenomenon. The present study aims to explore the prevalence of academic burnout and its relationship to personality dimensions and physical activity among Iranian medical students.

\section{Material and Methods}

\section{Study design and participants}

A cross-sectional correlational design was used to evaluate the prevalence of academic burnout and its associated factors among Iranian medical students. A total of 417 students were selected from three major cities of Iran through the stratified multistage sampling method, from May to August 2019. Finally, 400 medical students filled the questionnaires correctly. All participants were full-time university students in the field of medicine, and the majority (61\%) of them were female (see Table 1). The exclusion criteria consisted of a lack of cooperation and inappropriately filled questionnaires. The study protocol was approved by the Zahedan University of Medical Sciences Research Ethics Committee Reg no. IR.ZAUMS.REC.1398.190. and all
Table 1. Participants' demographic information

\begin{tabular}{ll}
\hline Variables & $(\mathbf{N = 4 0 0 )}, \mathbf{\%}$ \\
\hline Age & \\
$<24$ & 55.3 \\
$\geq 24$ & 44.7 \\
Gender & \\
Male & 39 \\
Female & 61 \\
Marital Status & \\
Single & 83.7 \\
Married & 16.3 \\
Years of Medical School & \\
First & 17 \\
Second & 14.4 \\
Third & 20 \\
Fourth & 19.3 \\
Other & 29.3 \\
\hline
\end{tabular}

procedures were in accordance with the latest version of the Declaration of Helsinki. Prior to participation, written informed consent was obtained from all participants and their parents/legal guardians after a comprehensive explanation of the study procedures. In order to comply with the standards included in the Declaration of Helsinki, participation was not mandatory and the subjects had the right to leave the study for any reason.

\section{Data collection}

After filling out the informed consent, participants received the demographic information form, Breso's Academic Burnout Questionnaire, Temperament and Character Inventory, and Baecke Physical Activity Questionnaire. The questionnaires were anonymous to keep the personal information of the patients completely confidential.

\section{Baecke Physical Activity Questionnaire}

The Baecke Physical Activity Questionnaire was used to assess physical activity. It is a 25-item questionnaire in three main domains, including work, sports, and leisure activities. The questions were asked on a five-point Likert scale. Measurements of physical activities were carried out by calculating the sum of the scores obtained from three main domains of physical activities. Sadeghisani et al. ${ }^{27}$ achieved an acceptable level of intraclass correlation coefficient (work scores $=0.95$, sport scores $=0.93$, and leisure scores $=0.77$ ) for the Persian version of Baecke Physical Activity Questionnaire. In my study, the Cronbach's alpha coefficients for the Baecke Physical Activity Questionnaire subscales of work scores, sport scores, and leisure scores were 0.93, 0.90, and 0.81, respectively, while it was 0.85 for the total scores.

\section{Temperament and Character Inventory}

Personality factors were measured using the 

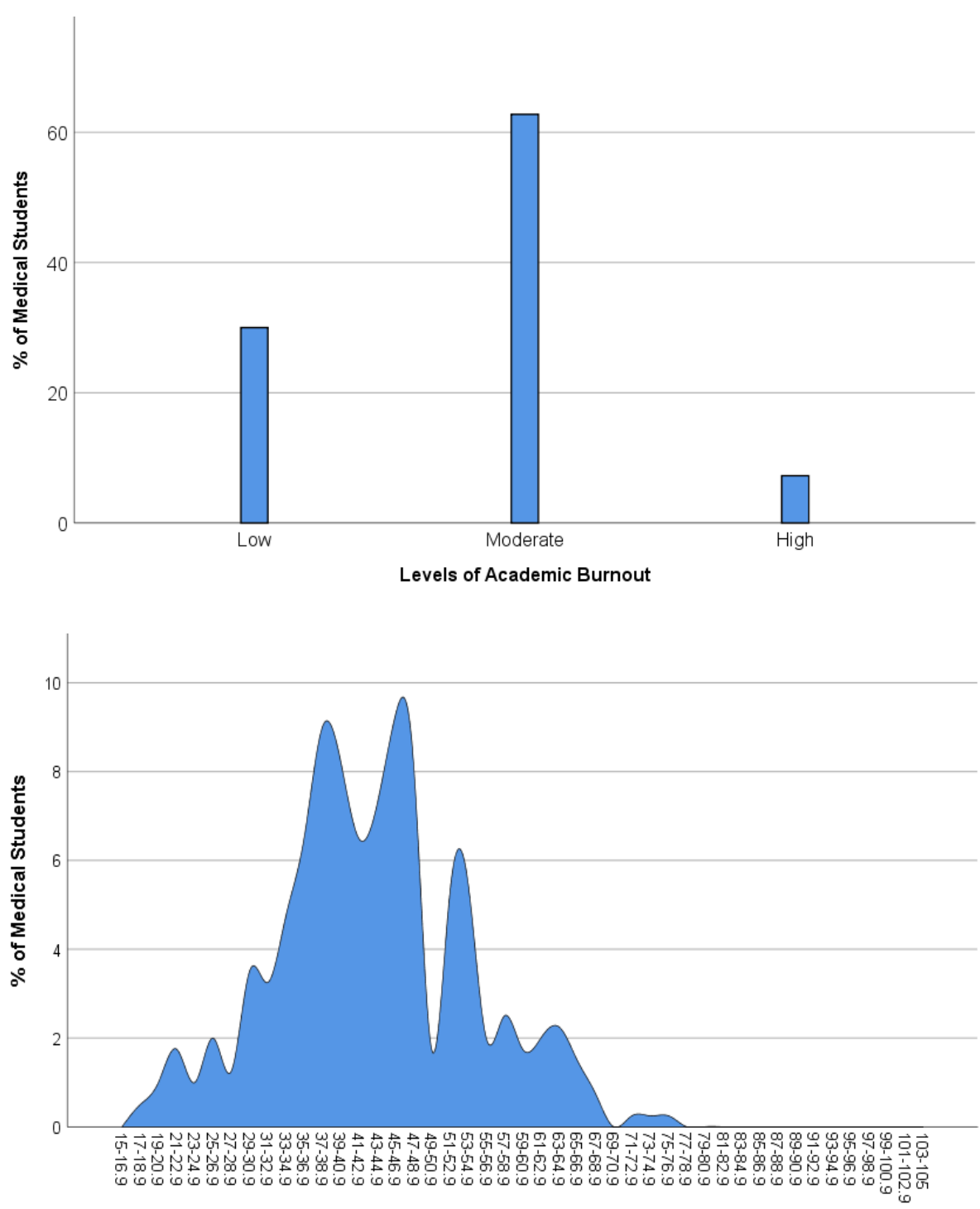

Scores of Academic Burnout

Fig 1. Top panel: Prevalence of low, moderate, and high levels of academic burnout in Iranian medical students; Bottom panel The distribution of Breso's Academic Burnout Questionnaire scores for Iranian medical students $(N=400)$

Note. Levels of academic burnout: Mild (15-37); Moderate (37-60); High (>60).

Temperament and Character Inventory. It is a 125-item questionnaire used to evaluate seven dimensions of personality, including novelty seeking, harm avoidance, reward dependence, and persistence (four temperament dimensions) and self-directedness, cooperativeness, and self-transcendence (three character dimensions). In Iran, factor analysis generates 6 scales, all with Cronbach's alpha levels ranging from 0.44 to 0.81 and test-retest correlations (Pearson's r) ranging from 0.53 to $0.86 .{ }^{28} \mathrm{In}$ my study, the Cronbach's alpha coefficients for the Temperament and Character Inventory subscales ranged from 0.63 to 0.88 .

\section{Breso’s Academic Burnout Questionnaire}

Burnout was evaluated through the Breso's Academic Burnout Questionnaire. It includes 15 items in the three domains of academic burnout, i.e., exhaustion, cynicism, and inefficacy (4, 5, and 6 items, respectively), scored on a seven-point Likert scale, ranging from 1 (strongly disagree) to 7 (strongly agree). The total score ranges from 15 to 105 . Low academic burnout is denoted by scores between 15 and 37; Moderate academic burnout occurs at the scores of 37-60; High academic burnout is indicated by scores above 60 . Also, the academic burnout 
Burnout of medical students: personality vs physical activity

Eur J Transl Myol 2021; 31 (1): 9411. doi: 10.4081/ejtm.2021.9411

Table 2. Comparison of the mean (M) and standard deviation (SD) of academic burnout and physical activity according to demographic characteristics $(N=400)$

\begin{tabular}{|c|c|c|c|c|c|c|}
\hline \multirow{2}{*}{ Variable } & \multicolumn{3}{|c|}{ Academic Burnout } & \multicolumn{3}{|c|}{ Physical Activity } \\
\hline & M(SD) & Test $^{\mathrm{a}}$ & $\mathbf{P}$ & M(SD) & Test $^{\mathbf{a}}$ & $\mathbf{P}$ \\
\hline \multicolumn{7}{|l|}{ Age } \\
\hline$<24$ & $42.26(10.23)$ & \multirow{2}{*}{$t_{(398)}=-1.76$} & \multirow{2}{*}{0.078} & $7.45(1.46)$ & \multirow{2}{*}{$\mathrm{t}_{(398)}=1.14$} & \multirow{2}{*}{0.254} \\
\hline$\geq 24$ & $44.15(11.15)$ & & & 7.28(1.58) & & \\
\hline \multicolumn{7}{|l|}{ Gender } \\
\hline Male & 44.39(11.76) & \multirow{2}{*}{$\mathrm{t}_{(288.53)}=1.85$} & \multirow{2}{*}{0.065} & $7.40(1.60)$ & \multirow{2}{*}{$\mathrm{t}_{(398)}=.27$} & \multirow{2}{*}{0.783} \\
\hline Female & $42.29(9.86)$ & & & 7.36(1.46) & & \\
\hline \multicolumn{7}{|c|}{ Marital Status } \\
\hline Single & 43.61(10.81) & \multirow{2}{*}{$\mathrm{t}_{(398)}=2.15$} & \multirow{2}{*}{0.032} & 7.30(1.48) & \multirow{2}{*}{$t_{(398)}=-2.25$} & \multirow{2}{*}{0.025} \\
\hline Married & $40.50(9.64)$ & & & 7.76(1.63) & & \\
\hline \multicolumn{7}{|c|}{ Years of Medical School } \\
\hline First $^{1}$ & $38.39(9.00)$ & \multirow{5}{*}{$\begin{array}{l}\mathrm{F}_{(4,395)}=8.87 \\
\text { Scheffé post- } \\
\text { hoc test: } \\
4 \& 5>1 \\
5>2 \& 3\end{array}$} & \multirow{5}{*}{$<0.001$} & $7.80(1.64)$ & \multirow{5}{*}{$\begin{array}{l}\mathrm{F}_{(4,395)}=3.57 \\
\text { Scheffé post- } \\
\text { hoc test: } \\
1>5\end{array}$} & \multirow{5}{*}{0.007} \\
\hline Second $^{2}$ & $40.8(9.56)$ & & & $7.49(1.21)$ & & \\
\hline Third $^{3}$ & $41.51(10.36)$ & & & $7.60(1.48)$ & & \\
\hline Fourth $^{4}$ & $46.01(10.45)$ & & & 7.14(1.67) & & \\
\hline Other ${ }^{5}$ & $46.16(11.11)$ & & & 7.07(1.43) & & \\
\hline
\end{tabular}

had a cut-off point score of 50 . Good reliability and validity of the questionnaire were reported by Marzoghi et al. ${ }^{29}$. In this study, the Cronbach's alpha coefficient for this questionnaire was 0.87 for the total scores.

\section{Statistical Analysis}

The data were analyzed using SPSS statistics version 25.0, and the statistical significance level was set at $\mathrm{p}<0.05$. The descriptive statistical measures, including the mean and standard deviation, were carried out for evaluating the data. The independent t-test and analysis of variance (ANOVA) were conducted to compare the mean and standard deviation of academic burnout and physical activity based on demographic characteristics. In the ANOVA, the Scheffé test was applied to a posthoc analysis. Pearson correlation coefficient (r) was also calculated to explore the relationship between the response (i.e., academic burnout) and explanatory variables (i.e., personality dimensions and physical activity). A hierarchical linear regression was performed to assess the moderating effect of physical activity on the relationship between dimensional personality traits and academic burnout, including the following steps. Control variables (including age, gender, marital status, and years of medical school), personality dimensions, and physical activity were used in the first, second, and third steps of the analysis, respectively. In the fourth step of the analysis, the two-way interactive sentences were employed.

\section{Results and Discussion}

Results

The prevalence of academic burnout was $25.5 \%$ ( $n=102)$, with heterogeneous levels (about $30 \%$ of the participants had low levels of academic burnout; about $62.75 \%$ had moderate levels; the remaining $7.25 \%$ had high levels) (see Figure $1 \mathrm{~A}$ and B). Furthermore, both of academic

Table 3. Simple correlation coefficient between explanatory variable and response variables $(N=400)$

\begin{tabular}{llll}
\hline Response variable & Explanatory variables & Pearson correlation coefficient (r) & P \\
\hline & Physical Activity & -0.62 & $<0.001$ \\
& Novelty Seeking & -0.28 & $<0.001$ \\
& Harm Avoidance & -0.10 & 0.030 \\
\multirow{2}{*}{ Academic Burnout } & Reward Dependence & -0.02 & 0.665 \\
& Persistence & -0.29 & $<0.001$ \\
& Self-Directedness & -0.35 & $<0.001$ \\
& Cooperativeness & -0.22 & $<0.001$ \\
& Self-Transcendence & 0.04 & 0.425 \\
\hline
\end{tabular}


Table 4. Regression to factors associated with academic burnout in medical students $(N=400)$

\begin{tabular}{|c|c|c|c|c|}
\hline \multicolumn{5}{|c|}{ Model \#1: Sociodemographic explanatory variables } \\
\hline Explanatory Variables & B & SE & Standardized Beta Coefficients & $\mathbf{P}$ \\
\hline Age & -1.61 & 1.27 & -0.07 & 0.207 \\
\hline Gender (male) & 1.92 & 1.04 & 0.08 & 0.65 \\
\hline Marital Status (married) & -3.49 & 1.41 & -0.12 & 0.014 \\
\hline Years of Medical School & 2.42 & 0.42 & 0.33 & $<0.001$ \\
\hline \multicolumn{5}{|c|}{ Model \#2: Sociodemographic and personality dimensions explanatory variables } \\
\hline \multicolumn{5}{|c|}{ Summary: $\mathrm{R}^{2}=0.31 ;$ Adjusted $\mathrm{R}^{2}=0.29 ; \mathrm{F}_{(9,390)}=19.74, \mathrm{p}<0.001 ; \Delta \mathrm{R}^{2}=0.20, \Delta \mathrm{F}_{(5,390)}=23.50, \mathrm{p}<0.001$} \\
\hline Explanatory Variables & B & SE & Standardized Beta Coefficients & $\mathbf{P}$ \\
\hline Age & -1.33 & 1.16 & -0.06 & 0.252 \\
\hline Gender (male) & 1.67 & 0.92 & 0.07 & 0.072 \\
\hline Marital Status (married) & -2.26 & 1.27 & -0.07 & 0.077 \\
\hline Years of Medical School & 2.12 & 0.38 & 0.28 & 0.001 \\
\hline Novelty Seeking & -0.53 & 0.13 & -0.19 & 0.001 \\
\hline Harm Avoidance & -0.08 & 0.19 & -0.02 & 0.675 \\
\hline Persistence & -1.78 & 0.41 & -0.18 & 0.001 \\
\hline Self-Directedness & -0.73 & 0.15 & -0.21 & 0.001 \\
\hline Cooperativeness & -0.68 & 0.22 & -0.15 & 0.003 \\
\hline \multicolumn{5}{|c|}{ Model \#3: Sociodemographic, personality dimensions, and physical activity explanatory variables } \\
\hline \multicolumn{5}{|c|}{ Summary: $\mathrm{R}^{2}=0.52$, Adjusted $\mathrm{R}^{2}=0.51, \mathrm{~F}_{(10,389)}=43.52, \mathrm{p}<0.001 ; \Delta \mathrm{R}^{2}=0.21, \Delta \mathrm{F}_{(1,389)}=177.25, \mathrm{p}<0.001$} \\
\hline Explanatory Variables & B & SE & Standardized Beta Coefficients & $\mathbf{P}$ \\
\hline Age & -1.25 & 0.96 & -0.05 & 0.194 \\
\hline Gender (male) & 1.97 & 0.76 & 0.09 & 0.011 \\
\hline Marital Status (married) & -0.52 & 1.06 & -0.01 & 0.624 \\
\hline Years of Medical School & 1.45 & 0.32 & 0.19 & 0.001 \\
\hline Novelty Seeking & -0.43 & 0.11 & -0.16 & 0.001 \\
\hline Harm Avoidance & -0.18 & 0.16 & -0.04 & 0.263 \\
\hline Persistence & -1.36 & 0.34 & -0.14 & 0.001 \\
\hline Self-Directedness & -0.28 & 0.13 & -0.08 & 0.038 \\
\hline Cooperativeness & -0.73 & 0.18 & -0.16 & 0.001 \\
\hline Physical Activity & -3.55 & 0.26 & -0.50 & 0.001 \\
\hline \multicolumn{5}{|c|}{ Model \#4: Sociodemographic, personality dimensions, physical activity, and two-way interactions } \\
\hline Explanatory Variables & B & SE & Standardized Beta Coefficients & $\mathbf{P}$ \\
\hline Age & -1.12 & 0.95 & -0.05 & 0.240 \\
\hline Gender (male) & 1.89 & 0.75 & 0.08 & 0.013 \\
\hline Marital Status (married) & -0.68 & 1.06 & -0.02 & 0.518 \\
\hline Years of Medical School & 1.37 & 0.32 & 0.18 & 0.001 \\
\hline Novelty Seeking & -1.43 & 0.52 & -0.53 & 0.006 \\
\hline Harm Avoidance & -0.74 & 0.82 & -0.19 & 0.372 \\
\hline Persistence & -1.54 & 1.65 & -0.16 & 0.352 \\
\hline Self-Directedness & -0.67 & 0.65 & -0.20 & 0.303 \\
\hline Cooperativeness & -2.45 & 0.94 & -0.55 & 0.010 \\
\hline Physical Activity & -8.59 & 1.49 & -1.22 & 0.001 \\
\hline Novelty Seeking $\times$ Physical Activity & -0.13 & 0.06 & -0.47 & 0.044 \\
\hline Harm Avoidance×Physical Activity & -0.12 & 0.11 & -0.27 & 0.266 \\
\hline Persistence×Physical Activity & -0.02 & 0.21 & -0.02 & 0.908 \\
\hline Self-Directedness $\times$ Physical Activity & -0.05 & 0.08 & -0.18 & 0.479 \\
\hline Cooperativeness $\times$ Physical Activity & -0.44 & 0.12 & -0.89 & 0.001 \\
\hline
\end{tabular}

burnout and physical activity mean scores had significant differences in marital status (respectively $\mathrm{t}_{(398)}=2.15$, $\mathrm{p}=0.032$ and $\left.\mathrm{t}_{(398)}=-2.25, \mathrm{p}=0.025\right)$ and years of medical school (respectively $\mathrm{F}_{(4,395)}=8.87, \mathrm{p}<0.001$ and $\mathrm{F}_{(4 \text {, }}$ $395)=3.57, p=0.007$ ) (see Table 2). After examining the correlations between study variables, the results revealed 
that scores of academic burnout were positively correlated with harm avoidance $\left(\mathrm{r}_{(388)}=-0.10, \mathrm{p}=0.030\right)$, whereas negatively correlated with novelty seeking $\left(\mathrm{r}_{(388)}=-0.28, \quad \mathrm{p}<0.001\right), \quad$ persistence $\quad\left(\mathrm{r}_{(388)}=-0.29\right.$, $\mathrm{p}<0.001)$, self-directedness $\quad\left(\mathrm{r}_{(388)}=-0.35, \quad \mathrm{p}<0.001\right)$, cooperativeness $\left(\mathrm{r}_{(388)}=-0.22, \mathrm{p}<0.001\right)$, and physical activity $\left(\mathrm{r}_{(388)}=-0.62, \mathrm{p}<0.001\right)$ (see Table 3 ). Moreover, the results of hierarchical linear regression indicated a significant contribution of marital status $(\beta=0.12$, $\mathrm{p}=0.014)$ and years of medical school $(\beta=0.33, \mathrm{p}<0.001)$ to the academic burnout in the first step (Table 4, Model 1) $\left(R^{2}=0.10\right)$. In the second step (Table 4 , Model 2$)$, a significant effect was found for novelty seeking $(\beta=-0.19$, $\mathrm{p}<0.001), \quad$ persistent $\quad(\beta=-0.18, \quad \mathrm{p}<0.001), \quad$ selfdirectedness $(\beta=-0.21, \mathrm{p}<0.001)$, and cooperativeness ( $\beta=-0.15, p=0.003$ ), after controlling age, gender, marital status, and years of medical school $\left(\Delta \mathrm{R}^{2}=0.20, \mathrm{p}<0.001\right)$. After incorporating the physical activity $(\beta=-0.50$, $\mathrm{p}<0.001$ ) in the regression (Table 4, Model 3), a significant amount of variance was added $\left(\Delta R^{2}=0.21\right.$, $\mathrm{p}<0.001$ ). In the final step (Table 4, Model 4), the twoway interactive effects of "novelty seeking $\times$ physical activity" $\quad(\beta=-0.47, \quad \mathrm{p}=0.044), \quad$ and "cooperativeness $\times$ physical activity" $(\beta=-0.89, p=0.001)$ received a relatively little amount of variance $\left(\Delta R^{2}=0.02\right.$, $\mathrm{p}=0.003)$. In addition, male gender $(\beta=0.08, \mathrm{p}=0.013)$, higher years of medical school $(\beta=0.18, p<0.001)$, and lower scores in novelty seeking $(\beta=-0.53, p=0.006)$, cooperativeness $(\beta=-0.55, \quad p=0.010)$, and physical activity $(\beta=-1.22, p<0.001)$ could be attributed to higher scores of academic burnout $\left(\mathrm{F}_{(15,384)}=31.21, \mathrm{p}<0.001\right.$, $\left.\mathrm{R}^{2}=0.53\right)$.

\section{Discussion}

This cross-sectional correlational study was performed to provide information on the prevalence of academic burnout and its association with personality dimensions and physical activity among Iranian medical students. The results showed that about one-fourth of participants had academic burnout, which was much lower than the rates in the United States and some European or Asian countries, 12,13,30,31 and might be explained by the "coping reservoir model”. Indeed, the coping reservoir metaphor is used to emphasize the dynamic nature of students' experiences, with potential consequences comprising enhanced resilience and mental health versus distress and burnout. ${ }^{32}$ Two main categories of factors were described by this model, contributing to well-being or burnout. They included depleting factors (negative input, namely internal conflicts, stress, and time and energy demands) and replenishing factors (positive factors, such as healthy activities, psychosocial support, intellectual stimulation, and mentorship). Based on this model, academic burnout occurs when the depleting factors dominate the replenishing factors. ${ }^{33}$ Thus, medical students in various societies may experience different levels of burnout syndrome depending on the degree of imbalance between depleting and replenishing factors. ${ }^{32,33}$ Besides, the heterogeneity of the burnout phenomenon in medical students contradicted the findings of earlier studies. ${ }^{12,13,30,31}$ Generally, the previous literature revealed that the majority of medical students had relatively higher levels of academic burnout, ${ }^{12,13,30,31}$ while the present study principally demonstrated the low to moderate levels of academic burnout. Comparison of the scores of academic burnout based on demographic characteristics demonstrated that the levels of academic burnout were higher among male medical students. This association was also confirmed in the regression analysis. This result agreed with that obtained by Santen et al., ${ }^{34}$ but contradicted the findings of Macilwraith and Bennett, ${ }^{23}$ Chin et al., ${ }^{31}$ and Willcock et al., ${ }^{35}$ who reported female medical students had significantly higher levels of academic burnout. Also, a recent study did not show any significant differences in burnout scores by gender. ${ }^{36}$ However, further investigations need to explain these contradictory findings. Moreover, the levels of academic burnout were significantly different based on the spending years in a medical school. As regards, so many students attend the medical school with altruistic values, the fantasy of healing the sick, and heroic images of themselves. They develop compulsive type A behavior patterns oriented toward achievement and approval. During the last years of medical school, the possibility of achieving these ideals could be seriously threatened, which might develop psychological distress.

Therefore, the process of academic burnout, due to excessive efforts to reach the unrealistic expectations imposed on an individual (by himself/herself or the society), may cause physical and mental exhaustion, leading to inefficacy. ${ }^{14,15}$

Furthermore, the mean scores of physical activity showed no difference regarding gender, which contradicted the results of previous studies. For example, Macilwraith and Bennett ${ }^{23}$ demonstrated that the mean scores of physical activity were higher in male medical students. In contrast, Webb et al. ${ }^{37}$ and Hao et al. ${ }^{38}$ conducted studies on 758 British and 6797 Chinese medical students, respectively, indicating that the mean scores of physical activity were higher in female students. In addition, the results showed that the levels of physical activity in medical students decreased during the medical course, which was consistent with earlier studies. ${ }^{39-41}$ This finding can be attributed to the increased burden of academic courses, tests, long work hours, occupational and professional claims, and responsibilities during the medical course. As a new finding, although the mean scores of academic burnout were lower for married students, no significant relationship was found between marital status and academic burnout in regression analysis. However, it is necessary to further investigate the association between marital status and academic burnout in future studies. As other findings, male gender, higher years of medical school, and lower scores in novelty seeking and cooperativeness were associated with higher scores of academic burnout among medical students. The obtained 
results were consistent with previous studies, ${ }^{18-21}$ but inconsistent with that obtained by Boni et al., ${ }^{42}$ who reported the first year medical students had significantly higher levels of academic burnout. Nevertheless, only Stoyanov and Cloninger identified a positive relationship between persistence and academic burnout in medical students. ${ }^{22}$ Basically, positive personality traits, such as optimism and energy, can act as a buffer against stressors and frustration, thereby preventing the development of inefficacy in medical students. ${ }^{17}$ Additionally, the present study showed a significant association between physical activity and academic burnout. This finding agreed with that obtained by Gerber et al., ${ }^{26}$ Lee et al., ${ }^{36}$ and Cecil et al. ${ }^{43}$ In contrast, it was inconsistent with the study of Macilwraith \& Bennett, ${ }^{23}$ who suggested that no significant relation was observed between physical activity and academic burnout. This study also investigated the moderating role of physical activity in the relationship between dimensional personality traits and academic burnout. Physical activity was found to have a moderating role in "novelty seeking-academic burnout" and "cooperativeness-academic burnout" relationships. This is because physical activity can decrease medical student academic burnout in different ways, including: i) Increasing the mastery learning and ability to counteract negative thoughts; ii) Modifying the emotional action tendencies as a fundamental therapeutic strategy; iii) Temporarily releasing individuals from stress and providing an opportunity to renew personal resources to re-confront occupational claims. ${ }^{43,44}$ Furthermore, physical activity can prevent academic burnout by decreasing the individual's physical vulnerability to stress since it increases heart rate, blood pressure, and the availability of central neurotransmitters including serotonin and endogenous opioids. ${ }^{45-47}$ The present findings have several potential implications. The heterogeneity of academic burnout in medical students might suggested that health professionals need to carefully assess the levels of academic burnout, rather than the assumption of high levels of academic burnout in all medical students. This individualized method can also be applied to the selection of suitable strategies for early or late preventive interventions. On the other hand, medical educators and health planners may need to consider gender, individual difference factors, and physical activity to address academic burnout among medical students. For instance, given the impact of physical activity on reducing the risk of burnout phenomenon among medical students, this factor can be used as a potential preventive element. In Iran, the physical education courses are restricted to the first two years of medical school. So, planning for a physical education class in higher years of medical course seems necessary. Eventually, identifying high-risk individuals would allow early intervention strategies to be incorporated into the medical school setting. Accordingly, medical schools should consider wellness curricula to help students understand the concept of academic burnout and its consequent effects on their performance and training This study was limited by its small sample size and participant selection from a restricted geographical area. Accordingly, the study results may not be generalized to other societies. In addition, a cross-sectional design using self-reported data cannot provide an accurate estimation of burnout syndrome and its causal relationships. Finally, based on negligible moderation effect of physical activity in the relationship between academic burnout and personality traits (i.e., novelty seeking and cooperativeness), medical educators and health planners should act with caution when designing interventions according to these findings. However, other factors associated with academic burnout among medical students (including social support, co-morbidity with other psychiatric disorders, and workload) should be addressed in future studies through panel studies.

In conclusion, this study aimed to examine the prevalence of academic burnout among Iranian medical students and its association with personality dimensions and physical activity. Approximately one-fourth of Iranian medical students may experience academic burnout. Gender, years of medical school, novelty seeking, cooperativeness, and physical activity were the associated factors for academic burnout among Iranian medical students. The results also suggested the moderating role of physical activity in the relationship between academic burnout and dimensional personality traits of novelty seeking and cooperativeness. Medical educators may need to consider these factors (particularly the benefits of physical activity) to address academic burnout syndrome. However, confirmatory longitudinal surveys are necessary.

\section{List of acronyms}

ANOVA - analysis of variance

HA - harm avoidance

NS - novelty seeking

PS - persistence

\section{Author contributions}

This is an article by one author

\section{Acknowledgments}

The author thanks the officials in charge of Zahedan University of Medical Sciences as well as the participants, who aided in conducting the present study.

\section{Funding}

None

\section{Conflict of Interest}

The author declares that he has no competing interests.

\section{Ethical Publication Statement}

We confirm that we have read the Journal's position on issues involved in ethical publication and affirm that this report is consistent with those guidelines. 


\section{Corresponding Author}

Mohsen Khosravi, MD, Department of Psychiatry and Clinical Psychology, Baharan Psychiatric Hospital, Zahedan University of Medical Sciences, Postal Code: 9813913777, Zahedan, Iran.

Tel: +98-5433522636, Fax: +98-5433518352.

ORCID iD: 0000-0003-2970-6309

E-mail: $\underline{\mathrm{dr} \text { khosravi2016@yahoo.com }}$

\section{References}

1. Charkhabi M, Abarghuei MA, Hayati D. The association of academic burnout with self-efficacy and quality of learning experience among Iranian students. Springerplus. 2013;2(1):677. doi: 10.1186/2193-1801-2-677.

2. Schaufeli WB, Martinez IM, Pinto AM, Salanova M, Bakker AB. Burnout and engagement in university students: A cross-national study. J Cross Cult Psychol. 2002;33(5):464-81. doi: 10.1177/0022022102033005003.

3. Kafry D, Pines A. The experience of tedium in life and work. Human Relations. 1980;33(7):477-503. doi: 10.1177/001872678003300703.

4. Dyrbye L, Shanafelt T. A narrative review on burnout experienced by medical students and residents. Med Educ. 2016;50(1):132-49. doi: 10.1111/medu.12927.

5. Maslach C, Jackson SE. The measurement of experienced burnout. J Organ Behav. 1981;2(2):99113. doi: 10.1002/job.4030020205.

6. Romani M, Ashkar K. Burnout among physicians. Libyan J Med. 2014;9(1):23556. doi: 10.3402/ljm. v9.23556.

7. Lee SJ, Choi YJ, Chae H. The effects of personality traits on academic burnout in Korean medical students. Integr Med Res. 2017;6(2):207-13. doi: 10.1016/j.imr.2017.03.005.

8. Lyndon MP, Henning MA, Alyami H, Krishna S, Zeng I, Yu TC, Hill AG. Burnout, quality of life, motivation, and academic achievement among medical students: A person-oriented approach. Perspect Med Educ. 2017;6(2):108-14. doi: 10.1007/s40037-017-0340-6.

9. ElKholy MM, El-Sayed ET, Sedrak AS, Raouf NA. Prevalence and Predictors of Burnout Syndrome among Medical Students of Cairo University. Egyptian Journal of Community Medicine. 2019;37(3):83-93. doi: 10.21608/ejcm.2019.43375.

10. Kumar S. Burnout and doctors: prevalence, prevention and intervention. Healthcare. 2016;4(3):37. doi: 10.3390/healthcare4030037.

11. Dyrbye LN, Thomas MR, Massie FS, Power DV, Eacker A, Harper W, Durning S, Moutier C, Szydlo DW, Novotny PJ, Sloan JA, Shanafelt TD. Burnout and suicidal ideation among US medical students. Ann Intern Med. 2008;149(5):334-41. doi: 10.7326/0003-4819-149-5-200809020-00008.
12. Erschens R, Keifenheim KE, Herrmann-Werner A, Loda T, Schwille-Kiuntke J, Bugaj TJ, Nikendei C, Huhn D, Zipfel S, Junne F. Professional burnout among medical students: Systematic literature review and meta-analysis. Med Teach. 2019;41(2):172-83. doi: 10.1080/0142159X.2018. 1457213.

13. Lian P, Sun Y, Ji Z, Li H, Peng J. Moving away from exhaustion: how core self-evaluations influence academic burnout. PLoS One. 2014;9(1):e87152. doi: 10.1371/journal.pone.0087152.

14. Zhang Y, Gan Y, Cham H. Perfectionism, academic burnout and engagement among Chinese college students: A structural equation modeling analysis. Pers Individ Dif. 2007;43(6):1529-40. doi: 10.1016/j.paid.2007.04.010.

15. Yang HJ, Farn CK. An investigation the factors affecting MIS student burnout in technicalvocational college. Comput Human Behav. 2005;21(6):917-32. doi: 10.1016/j.chb.2004.03.001.

16. Slivar B. The syndrome of burnout, self-image, and anxiety with grammar school students. Horizons of Psychology. 2001;10(2):21-32.

17. Jacobs SR, Dodd D. Student burnout as a function of personality, social support, and workload. J Coll Stud Dev. 2003;44(3):291-303. doi: 10.1353/csd. 2003.0028.

18. Jiang N, Sato T, Hara T, Takedomi Y, Ozaki I, Yamada S. Correlations between trait anxiety, personality and fatigue: study based on the Temperament and Character Inventory. J Psychosom Res. 2003;55(6):493-500. doi: 10.1016/ s0022-3999(03)00021-7.

19. Raycheva RD, Asenova RS, Kazakov DN, Yordanov SY, Tarnovska T, Stoyanov DS. The vulnerability to burn out in healthcare personnel according to the Stoyanov-Cloninger model: evidence from a pilot study. Int J Pers Cent Med. 2012;2(3):552-63. https://doi.org/10.5750/ijpcm.v2i3.260

20. Melchers MC, Plieger T, Meermann R, Reuter M. Differentiating burnout from depression: personality matters! Front Psychiatry. 2015;6:113. doi: 10.3389/fpsyt.2015.00113.

21. Yazici AB, Esen O, Yazici E, Esen H, Ince M. The relationship between temperament and character traits and burnout among nurses. Journal of Psychology \& Psychotherapy. 2014;4(5):1-5. doi: 10.4172/2161-0487.1000154.

22. Stoyanov DS, Cloninger CR. Relation of peoplecentered public health and person-centered healthcare management: a case study to reduce burnout. Int J Pers Cent Med. 2012;2(1):90-5.

23. Macilwrait P, Bennett D. Burnout and physical activity in medical students. Ir Med J. 2018;111(3):707.

24. Khosravi M, Mirbahaadin M, Kasaeiyan R. Understanding the influence of high novelty-seeking 
on academic burnout: Moderating effect of physical activity. Eur J Transl Myol. 2020;30(2):318-24. doi: 10.4081/ejtm.2019.8722.

25. Weight CJ, Sellon JL, Lessard-Anderson CR, Shanafelt TD, Olsen KD, Laskowski ER. Physical activity, quality of life, and burnout among physician trainees: the effect of a team-based, incentivized exercise program. Mayo Clin Proc. 2013;88(12):1435-42. doi: 10.1016/j.mayocp.2013. 09.010 .

26. Gerber M, Brand S, Elliot C, Holsboer-Trachsler E, Pühse U, Beck J. Aerobic exercise training and burnout: a pilot study with male participants suffering from burnout. BMC Res Notes. 2013;6:78. doi: 10.1186/1756-0500-6-78.

27. Sadeghisani M, Manshadi FD, Azimi H, Montazeri A. Validity and reliability of the Persian version of Baecke habitual physical activity questionnaire in healthy subjects. Asian journal of sports medicine. Asian J Sports Med. 2016;7(3):e31778. doi: 10.5812/asjsm.31778.

28. Dadfar M, Bahrami F, Dadfar F, Younesi SJ. Reliability and validity of the Temperament and Character Inventory. Journal of Rehabilitation. 2010;11(3):15-24. (Persian)

29. Marzoghi R, Haidari M, Haidari A. The impact of educational justice on students' academic burnout in the University of Social Welfare and Rehabilitation Science, Tehran, Iran. Strides in Development of Medical Education Journal. 2012;10(3):328-34. (Persian)

30. Dyrbye LN, West CP, Satele D, Boone S, Tan L, Sloan J, Shanafelt TD. Burnout among US medical students, residents, and early career physicians relative to the general US population. Acad Med. 2014;89(3):443-51. doi: 10.1097/ACM.000000000 0000134.

31. Chin RW, Chua YY, Chu MN, Yusoff MSB, Wong MS, Lee YY Prevalence of Burnout among Universiti Sains Malaysia Medical Students. Education in Medicine Journal. 2016;8(3):61-74. doi: 10.5959/eimj.v8i3.454.

32. Dunn LB, Iglewicz A, Moutier C. A conceptual model of medical student well-being: promoting resilience and preventing burnout. Acad Psychiatry. 2008;32(1):44-53. doi: 10.1176/appi.ap.32.1.44.

33. Dyrbye LN, Thomas MR, Huntington JL, Lawson KL, Novotny PJ, Sloan JA, Shanafelt TD.Personal life events and medical student burnout: a multicenter study. Acad Med. 2006;81(4):374-84. doi: 10.1097/00001888-200604000-00010.

34. Santen SA, Holt DB, Kemp JD, Hemphill RR. Burnout in medical students: examining the prevalence and associated factors. South Med J. 2010;103(8):758-63. doi: 10.1097/SMJ.0b013e 3181e6d6d4.
35. Willcock SM, Daly MG, Tennant CC, Allard BJ. Burnout and psychiatric morbidity in new medical graduates. Med J Aust. 2004;181(7):357-60.

36. Lee KP, Yeung N, Wong C, Yip B, Luk LH, Wong S. Prevalence of medical students' burnout and its associated demographics and lifestyle factors in Hong Kong. PLoS One. 2020;15(7):e0235154. doi: 10.1371/journal.pone.0235154.

37. Webb E, Ashton CH, Kelly P, Kamali F. An update on British medical students' lifestyles. Med Educ. 1998;32(3):325-31. doi: 10.1046/j.1365-2923.1998. 00204.X.

38. Hao W, Yi H, Liu Z, GaoY, Eshita Y, Guo W, Zhang $\mathrm{H}$, Sun J. Gender comparisons of physical fitness indexes in Inner Mongolia medical students in China. Glob J Health Sci. 2014;7(1):220-7. doi: 10.5539/gjhs.v7n1p220.

39. Ball S, Bax A. Self-care in medical education: effectiveness of health-habits interventions for firstyear medical students. Acad Med. 2002;77(9):9117. doi: 10.1097/00001888-200209000-00023.

40. Frank E, Carrera JS, Elon L, Hertzberg VS. Basic demographics, health practices, and health status of US medical students. Am J Prev Med. 2006;31(6):499-505. 10.1016/j.amepre.2006.08.009.

41. Peterson DF, Degenhardt BF, Smith CM. Correlation between prior exercise and present health and fitness status of entering medical students. J Am Osteopath Assoc. 2003;103(8):361-6.

42. Boni RA, Paiva CE, De Oliveira MA, Lucchetti G, Fregnani JH, Paiva BS. Burnout among medical students during the first years of undergraduate school: Prevalence and associated factors. PLoS One. 2018;13(3):e0191746. doi: 10.1371/journal. pone.0191746.

43. Cecil J, McHale C, Hart J, Laidlaw A. Behavior and burnout in medical students. Med Educ Online. 2014;19(1):25209. doi: 10.3402/meo.v19.25209.

44. Barlow DH, Allen LB, Choate ML. Toward a unified treatment for emotional disorders-republished article. Behav Ther. 2016;47(6):838-53. doi: 10.1016/j.beth.2016.11.005.

45. Likus W, Milka D, Bajor G, Jachacz-Lopata M, Dorzak B. Dietary habits and physical activity in students from the Medical University of Silesia in Poland. Rocz Panstw Zakl Hig. 2013;64(4):317-24.

46. Armon G. Type D personality and job burnout: The moderating role of physical activity. Pers Individ Dif. 2014;58:112-5. doi: 10.1016/j.paid.2013. 10.020.

47. Lumley S, Ward P, Roberts L, Mann JP. Selfreported extracurricular activity, academic success, and quality of life in UK medical students. Int J Med Educ. 2015;6:111-7. doi: 10.5116/ijme.55f8.5f04.

Submission: October 19, 2020 Accepted for publication: November 17, 2020 